\title{
Diálogo con CpS acerca del diálogo Cristiano-Marxista
}

Por Matías GABCIA

Sumario:

1. AMBITO $Y$ CONDICIONES DEL. DIALOGO: A) Ambito del diálogo. B) Superación de los dogmatismos cerrados (pot parte cristiana; por parte marxista).

II. PnEGUNTAS A LOS CpS: A) Tipología de CpS y problemática que ella suscita fpor la forma de llegar del cristianismo a la opción marxista; por la forma de concretar los objeti. vos que se derivan de esa doble opción; por la forma de intentar armonizar las posibles contradicciones; por el tipo de marxismo adoptado). B) Justificación de la opción por el socialismo marxlsta (motivaciones de la opción; racionalidad de optar por los contenidos del socialismo marxis. ta; racionalidad política de la misma opción). C) Compatibllidad del marxismo con el cristianismo (el monismo de la ideologia marxista; la praxis politica; otras cuestiones).

III. RESUlTAdos posibles del DIALOGO CAISTIANOMARXISTA: A) Acercamiento recíproco y profundización de cada dialogante en sulínea especifica. B) Desaparición de una de las partes. C) Conclusión: aceptación del reto y juego
limpio.

Las reflexiones que se recogen en estas páginas responden principalmente a una voluntad de sincero diálogo con esos hermanos nuestros en la fe que han hecho la opción por el socialismo marxista y que, desde la doble fidelidad a la fe cristiana y al marxismo, integran el movimiento de CPS. Diálogo sincero, en el sentido de acercarnos a ellos con simpatía y dispuestos a dejarnos interpelar por sus razones, sus motivaciones y su ejemplo; pero sincero también en el sentido de no ocultar los interrogantes que honradamente nos salen al paso. 
La reciprocidad de esta voluntad de diálogo queda testimoniada en la siguiente cita de uno de los pensadores más carac. terizados del movimiento en España: Juan N. García Nieto, que en este mismo número de la REVISTA DE FOMENTO SOCIAL. escribe también sobre el tema. La cita, aunque un poco larga, la transcribimos sin recortes, pues su contenido nos puede ayudar a situar adecuadamente el tema:

-A nadie de nosotros se le oculta lo ambicioso de la tarea que nos hemos propuesto, y que centra uno de nuestros esfuerzos diarios en la reflexión y en la milstancia. No nos engaríabamos en Avila, cuando afirmábamos que se nos iban a presentar serias y graves dificultades. "Somos conscientes-deciamos entonces-de que el marxismo se basa en una teoria dialéctica que excluye toda trascendencia, si bien no olvidamos tampoco que la clencia, como análisis histórico de las contradicciones de la realidad social, queda más allá de toda afirmación o negación de Dios."

Es éste un camino en el que, si bien a nivel de práctica y de militoncia politica, se han solucionado problemas históricos notables, a nivel ideológico nos queda, a marxistas no creyentes y a marxistas creyentes, un largo camino por recorrer. Es cierto que ante nosotros yo no se presenta un solo marxismo monolitico e identificado con concepclones rigidas y dogmáticas. Hoy nos encontramos con diver. sos marxismos, y todos ellos, más o menos explicitamente, se plan. tean seriamente problemas muy similares a los que nos planteamos los creyentes. A todos se nos abre un nuevo reto, que intentamos afrontar con seriedad y $\sin$ sectarismos, preguntandonos a qué he. rencia debemos renunciar unos y otros, sin ser infieles a la historia,

Es éste un camno no fácil, pero quienes nos encontramos ya codo a coto en una misma opción politica, nos estamos preguntando constantemente quienes somos, en qués creemos, en qué esperamos, qué nos une. Aquí, pues, se encuentra una de nuestras más importantes tareas, y en la que encontramos ayuda a través de la critica constructiva y estimulante de los que en la lglesla no piensan como nosotros, pero nos aceptan como hermanos en una misma fe y no nos rechazan.

lgualmente no dejan de ser reveladoras y estimulantes palabras que brotan de grupos politicos vinculados a las raices históricas de los movimientos sociatistas y comunistas de nuestro país. Entre otras mencionamos éstas. especialmente signillcativas: "La existencia, dentro de nuestro partido, de compañeros a los que su militancia marxista no solamente no ha puesto en "peligro" su fe cristlana, sino que la ha reforzado, es una notabla aportactón al avance de la teoría y de la práctica marxista, tanto en nuestra casa como en ol conjunto del movimiento obreron ("Trebal", 18 de marzo de 1975)" (1).

El tema que elegimos para iniciar nuestro diálogo con esos muestros hermanos en la fe que integran la corriente de CpS nos viene marcado por las palabras citadas. Versará sobre esa importante tarea, en la que ellos con especial intensidad se han

(1) 1. N. GARGIA NETO: Feencuentro con los "Cristianos por el Soclalismon, Iglesia Viva, n. 60 (1975), 507-508. 
embarcado y para cuya recta realización piden y aceptan la ayuda de otros cristianos: el encuentro cristiano-marxista y el dlálogo.

En una primera parte damos nuestra opinión sobre las condiciones que nos parecen indispensables para que el diálogo tenga perspectivas de éxito. A continuación proporcionamos un catálogo de las principales cuestiones concretas que en nuestra opinión deben ser abordadas en ese diálogo, tal como se plan. tea en el seno de CpS. Finalmente intentamos imaginarnos los ridad y resultados de él, si se aborda y prosigue con since-

\section{1.-AMBITOS $Y$ CONDICIONES DE DIALOGO}

Muy de la mano de las afimaciones hechas en la clia inicial, hacemos por muestra parte las sigulentes aclaraciones intro-
ductorias:

\section{A) El ámbito del diálogo.}

La cita de García Nieto nos ayuda en primer lugar a com prender que el restringido-maunque legítimo-diálogo interno de CpS sólo adquiere su verdadero horizonte en un ámbito de día logo mucho más amplio: un ámbito en el que quepan también marxistas no creyentes y cristianos que-al menos todavía-no pueden colocarse en la perspectiva de cps. Con ello no quiero únicamente decir que ambas categorías de personas ajenas al movimiento puedan y deban dialogar-segun lo postula explicitamente García Nieto-con los miembros de CpS, sino también que pueden y deben hacerlo directamente entre si.

Que nadie vea en esta afirmación un intento de marginar a los CpS del diálogo cristianomarxista y de resituar a éste en sus términos tradicionales, mucho menos comprometidos. Todo ción contrario: acepto como un hecho-en cuya posible justificación entraré más adelante-la existencia de CpS; a partir de ese hecho estoy convencido de que la mera existencia de un grupo de cristianos que, sin renegar de su fe, han optado por el socialismo marxista (aum a sabiendas de que viven la doble fidelidad en una unidad dialéctica llena de tensiones, y tal vez de contradicciones no resueltas aporta al diálogo cristiano marxista un nuevo clime de sinceridad y distensión. 
Pero ese mismo hecho y esa voluntad de dificil undad entraña por su propla dinámica la tendencia y el peligro de enmascarar los conflictos tras fáclles amonizaciones verbales, $y$, por el temor de romper la frágil unidad, de aplazar indefinidamente sut resolución en profundidad. Si eso ocurriese-aun contra la voluntad de los CpS-, más tarde o más temprano volverian a rebrotar fustradoramente las contradicciones. Por ello, si la pre. sencia de Cps enriquece el clima de diálogo, aportándole por patte cristiana distensión, credibilidad, voluntad de cambio y mulua confianza, la participación en él de marxistas no creyentes y de creyentes no marxistas le aseguran la seriedad y el rigor que haran que los posibles avances no se reduzcan a sim. ples armonizaciones verbalss $y$, en el fondo, ficticias de las contradicciones.

\section{B) Superación de los dogmatismos cerrados.}

Con esta litima observación entramos en otro aspecto del planteamiento del diálogo. Todo diálogo supone una capacidad y una disposición de cambio, lo que a su vez implica una renun cia a actitudes cerradamente dogmáticas (2). El que cree tener toda la verdad sin mezcla de error será tal vez capaz de discutir y polemizar, pero no está capacitado para dialogar, pues no está dispuesto a aprender nada ni a corregir nada. Ni siquiera está en disposición de enriquecer y mejorar, por el influjo del otro dialogante, la perspectiva desde la que él contempla el núcleo de verdad prolunda que lat vez posee. En esta linea, García Nieto nos habla de "un nuevo reto que intentamos afrontar con serenidad y sin sectarismos, preguntándonos a qué herencia de. bemos renunciar unos y otros, sin ser infieles a la historian.

La capacidad y disposición de cambio de que estamos tratan do no basta que sea subjetiva. Para que la confrontación ideologica entre dos movinientos históricos tan caracterizados como el cristianismo y el marxismo conduzcan a algo más que a apostasías o conversiones en una u otra dirección, es preciso que la flexibilidad dialogal afecte a la entraña misma de ambas realidades. Sólo así la flexibilidad subjetiva podrá significar verdadero acercamiento y no simple abandono y traición a una de las dos posibles fidelidades.

1. Para el cristiano, esta actitud es posible desde el momento en que admitimos alguna distinción entre fe y compreri-

(2) La expresión se utiliza aqui en su sentido vulgar, explicado a continuación en of texto. No alude, por tanto, a los adogmas" en su sentido técnico teológico, cuya aceptación y mantenimlento como luego veremoses concordable con una actitud no acerradamente dogmátican. Véase también la nota 12 final. 
sión de la te. La te y su contenido objetivo es irrenunclable: en cambio, la comprensión teórica y práctica de la fo es perfeccionable y purificable. El cristiano afronta, acepta e incluso desea la lucha y la confrontación ideologica, aun a sabiendas de que ella le obligará tal vez a abandonar determinados esquemas mentales y determinadas actitudes prácticas, con las que ha pensado y desde las que ha vivido en ciertas épocas su fe. Más aún. en la medida en que dicha confrontación se lleve a cabo con seriedad, sin manipulaciones y sin eludir ni enmascarar las dificultades, el cristiano sabe que la fe saldrá de ahí purificada y robustecida. Evidentemente, ello es imposible desde una actitud integrista, que identifica la fe con su envoltura cultural y que incluso se niega a superar aquellos condicionamientos culturales, que tal vez no son sino camuflajes ideológicos de actitudes interesadas, en pugna objetiva con las exigencias de la misma fe.

Esto es necesario subrayarlo, porque en tiltimo término la confrontación ideológica y cultural que propugnamos no pode. mos entenderla como un juicio a que una determinada cultura (en este caso la marxista) someta como juer inapelable a la fe, con la pretensión de domesticarla y someterla a su medida. Sin llegar a esa desmesura, la confrontación puede conseguir más todavia: en cuanto que aporta un muevo horizonte de com. prensión y de posible acción. es capaz de liberar y estimular el propio dinamismo de la fe, permitiéndole adquirir conciencia de las limitaciones e incluso contradicciones consigo misma, en que le obligó a vivir encerrada el anterior horizonte. Al final dei proceso de confrontación y en la medida en que la cultura mar. xista se muestre capaz de aportar un nuevo y mís rico-si bien siempre limitado -..-horizonte de comprensión y realización para ciertos aspectos del cristianismo, se podrá ver que la importancia y el fruto de la confrontación no estará tanto en haber hecho al cristianismo más marxista, sino en haberlo hecho más cristiano.

2. En reciprocidad con to dicho hasta ahora, el diálogo exige además que se abandone igualmente por parte marxista toda actitud integrista y dogmática. También aquí nos parece que hay apoyaturas para pensar que ello es posible, tanto a nivel de flexibilidad subjetiva, como incluso a ese nivel más profundo y decisivo de la capacidad evolutiva del mismo sistema, sin por ello negarse radicalmente a sí mismo. En el texto tantas veces aludido de García Nieto hay referencias a ambos aspectos.

En cuanto al primero, nos recordaba que "ante nosotros ya no se presenta un solo marxismo monolítico e identificado con concepciones rigidas y dogmáticas. Hoy nos encontramos con diversos marxismos, y lodos ellos, más o menos explicitamente. se plantean seriamente problemas muy similares a los que nos planteamos los creyentes". 
En cuanto al segundo aspocto del fue trataromos con más molundidad más adelante-wástenos pot ahora aludir a la posible distincion entre estos dos niveles de comprensión del mar. xismo: por un lado, un marxismo basado "en una teoría daléc tica que excluye toda trascendencia"; por otro, una "cienclan marxista, "como análisis histórico de las contracciones de la realidad social", que, en cuanto tal ciencia, "queda más allá de toda afimación o negación de Dios".

Continuando el paralelismo iniciado, podemos también afirmar lo siquiente: asi como rechazamos una concepción del diálogo cristiano-marxista en la que el marxismo se erigiese en juez y reductor de la fe, así tampoco pedimos el que la fe se erija en luez y reductora del marxismo. Por ese camino, las concesiones y compromisos a que se llegase serian siempre etimeros. Lo que en ambos aspectos postulamos es menos y es más: asi como la confrontación de la fe con las culturas centre ellas la marxistal puede perfeccionar la autocomprensión y la coherencia vital de la fe en su proyección práctica, asi también creemos que la confrontacion dal marxismo con la fe puede estimular a aquél a profundizar en su propia racionalidad clentifica y en la coherencia préctica con ella.

En definitiva, lo que aceptamos 0 incluso pedimos es que el cristianismo renuncie a encerrarse e identificarse con una determinada cultura (burguesa o marxista), e igualmente que el marxismo no actúe y proceda como si fuese una fe y una religión. Pedimos que cada uno se confronte con el otro desde su propio nivel $y$, estimulados por esa confrontación, intenten acercarse mufuamente a partir de su propia dinámica.

\section{1.-PREQUNTAS A LOS CpS}

Sobre la base de lo dicho hasta ahora, el catálogo de preguntas y sugerencias a los $C p S$, que en esta segunda parte intentamos recoger, tal vez se deje sistematizar en estos tres apartados: Ante todo esbozamos una descripción y una tipología de las diversas formas de enfocar el problema los CpS. En segundo lugar abordaremos las cuestiones que suscita su opción por el socialismo marxista, con independencia de la componibilidad con la fe cristiana. En tercer lugar trataremos especificamente de esa concordabilidad.

A) Tipología de $\operatorname{cps}$ y problemática que ella suscita.

Unicamente nos interesan aquí aquellos aspectos tipológicos de CpS que inciden directamente en la forma de concebir la 
confrontación cristiano-marxista. Ello, a su vez, puede considerarso doste osto cuathuplo punto do vista:

1. Por la forma de llegar desde el cristianismo a la opción marxista. Los mismos CPS nos proporchonan esta tipologia, al hablarnos de dos caminos o itinerarios que conducen a la situación de simultaneidad en la fe y en la opción marxista (3). Unas veces se trata simplemente de cristianos a los que las circuns. tancias político-sociales, con independencia de motivaciones de fe, les despertaron la conciencia de clase, les introdujeron en la lucha revolucionaria y les abrieron los ojos para la aceptación de la interpretación marxista de todo ese proceso. Sólo en un segundo momento les surge a esos cristianos, ya marxistas, el problema de la concordabilidad de la nueva opción con su fe, lo que a su vez suele conducir, bien a un abandono de la fe, bien a un intento de concordar ambas opciones.

En otras ocasiones es una fe profundamente vivida la que impulsa a ciertos cristianos a buscar la forma concreta de asu. mir los compromisos históricos que la misma fe exige: la praxis y la teoria marxistas les salen entonces al maso, y en ellas creen descubrir-no por la fo, sino por la fuerza de su propia racionalidad intema-el único modo eficaz de realizar la tarea liberadora a la que la le los impulsa. Evidentemente, tamblén aquí se plantea el problema de la componibilidad de la fe con ciertos aspectos de la praxis y la teoría marxistas.

2. Por la forma de concretar los objetivos que se derivan de esa doble opción. Los dos itinerarios conducen, por lo tanto. al mismo resultado: una situación de simultaneidad problemática en la fe y en la opción marxista. Dicha simultaneidad en la doble opción determina a su vez los dos grandes objetivos del movimiento de CpS: la defensa y la promoción de la fe (finalidad pastoral) y la colaboración en la construcción del socialismo (finalidad socio-politica) (4).

(3) En todo este articulo, ya excesivamente largo, vamos a ser muy parcos en las notas y referencias, que de suyo deberian respaldar cada una de nuestras nfimaciones. Sobre este punto patticular verase, $p$ ejemplo. U. N. GARCIA NIETO: Fe cristiana y lucha de clases, En FERROMATE (ed,), Cristianos por el Socialismo (Ed. Verbo Divino). Estella, 1975, 95-100. En general, para una iniciación en el conocimiento del movimiento, renilimos al lector al Apéndice documental que publicamos en este mismo número de la Revista y a una serie de colaboraciones aparecidas en el libro al que acabamos de aludir, editado bajo la dirección de FIERROMATE, y en el nímero 60 de la revista Iglesia Viva, citada en la nota $t$. Véase tarnbién el número doble 5253 (1974) de dicha revista, dedicado también de modo mo-
nogrático al tema de CpS.

(4) Los dos objetivos fundamentales estan claramente definidos por J. N. GARCIA NIETO, a. G. (nota 1), p. 503-504. Alli se insfuian tamblén algunos de los objetivos secundatios que siven para instrumentar los dos principales. La sistematizacion del texto es nuestra y con ella intentamos reunir en unidad coherente diversas manifestaciones de los CpS. 
Los CpS se senalan también otros objetivos, que, lógicamente. tienen un carácter instrumental en relación a las dos finalidades básicas. La mayor o menor acentuación de una u otra de esas dos findidades y, sobre todo, la manera de orientar y subrayar los objetivos que hemos llamado instrumontales da base para nuevas diferenciaciones tipológicas.

a) En relación a la finalidad socio-politica, un primer objetivo es el trabajar por conseguir votos y apoyo en favor de los partidos de izquierda de inspiración marxista, y para ello impedir - contrarrestar una posible acción de la jerarquia de la lglesia en semtido opuesto, basada en la inaceptabllidad del marxismo para los cristianos. Este segundo objetivo lo expresan tambien como exigencia de un pluralismo real en la lglesia, que no elimi ne de entrada del abanico de las legitimas posibilidades a ninguno de los diversos marxismos. En esta misma línea, pero a un nivel de mayor profundidad, se sitúa otro de los grandes objetivos del movimiento: la lucha ideológica dentro de la lglesia, que debe conducir a una purificación y desideologización de la fe, de forma que ésta pueda desprenderse de los esquemas de pensamiento y de acción en los que vive cautiva y secuestrada por la mentalidad burguesa. La concepción que los CpS tienen de la lucha ideológica les inclina en ocasiones a proclamar a la opción marxista como la única coherente con un cristianismo bien entendido; más aún, a veces dan la impresión de que su ideal seria lograr que el pluralismo aceptable para un cristiano se limitase al abanico de las diversas opciones mar. xistas. Es verdad cue a partir de Quebec se han matizado y moderado mucho afimaciones de este gonero, pero la tendencia no creemos que esté eliminada. El útimo objetivo, que sirve también a la finalidad politica, pero que se conecta más directamente con la finalidad pastoral, to constituye la reformulación de la fe, que por lo demás no es sino el aspecto positivo de la lucha ideológica y que, como ella, puede entenderse con muy diversa radicalidad.

b) Sería falso e injusto ver en estos objetivos únicamente instrumentaciones de la que hemos llamado finalidad socio-polí tica. Los CpS pretenden también servir con ello, y muy since. ramente, a la finalidad pastoral de defensa y promoción de la fe. Evidentemente nos estamos refiriendo, sobre todo, a los tres últimamente descritos, es decir, a la ampliación del pluralismo eclesial, a la lucha ideológica y a la reformulación de la fe. Bastantes miembros de CpS-sobre todo, sacerdotes-. que trabajan en él con una orientación pastoral prevalente, opinan que la estrechez (juridica o sociológica) del marco eclesial y la secuestrada comprensión oficial y ambiental de la fe es lo que provoca falsas incompatibilidades con el marxismo, que arrojan indebidamente del seno del cristianismo y de la lglesia a muchos cristanos que podrian y deberian permanecer en ella. Mientras 
eso no se consigue, uno de los principales servicios que Cps ptetende hacer a la fe es proporcionar a los cristianos compro. metidos nuevos espacios para vivir y desarrollar la te, sin verse psicológleamente obligados a romper con la comunidad ectesial. Pero hay más; ollos opinan quo una fe desideologizada y reformulada sería en si misma una fe más pura y auténtica.

Como una forma de servicio especifico a la fe hay también que considerar otra de las tareas a objetivos que se han propuesto a si mismos los $\mathrm{CpS}$, aquella precisamente que está cons. tituyendo el tema central de nuestras reflexiones: la promoción del diálogo cristiano-marxista.

¿Qué deberiamos decir ante estos planteamientos? La mera descripción, que hemos procurado hacer con la mayor objetividad, descubre la seriedad, pero también la peligrosidad del in. tento. Ante él vamos a limitarnos por ahora a esta única observación crítica, que no afecta a ninguno de los detalles, sino al planteamiento global. Tememos que todo él adolezca de un claro desequilibrio. A la te y a la lglesia se les somete sin limitaciones a una crítica despiadada desde los presupuestos marxistas; an cambio, apenas se permite que el mecanismo critico funcione en sentido opuesto. Da la impresión de que la lqlesia tiene que cambiar todo aquello que sea inaceptable para el marxismo (o, to que es lo mismo, para los CpS en cuanto marxistas), y que a éste se le conceden todos los derechos en orden a exigir esos cambios. Es verdad que en todo ello se opera sobre la suposición de que las modificaciones que de esa forma se exilan sólo afectarán a las idoologias en que esté encerrada la $\mathrm{fe}$, no a la fe misma. Pero ello es sólo in presuptesto no probado. Por otro lado, a la Iglesia parece exigirsele que se abra a un pluralismo, en cuyo ámbito se acepten sin más todas las corrientes marxistas, lo que implícitamente comporta la aceptación de todos los contenidos de ellas; parece que se le niega, por tanto, el derecho a expresar la incompatibilidad de alguno de esos contenidos o actitudes con la fe; si se insinúa alguna excepción. iria precisamente en la linea de la exclusión de las opciones no socialistas.

3. Por la forma de intentar armonizar las posibles contra* dicciones. La crítica que acabamos de hacer a algo que nos parece tiene el peligro de constituir el enfoque global del movi. miento no seria justa si no añadiésemos en seguida que ese peligro coexiste con su antídoto, es decir, con la conciencia, la preocupación y la confesión, por parte de muchos de sus miembros más calificados. de que les quedan ain muchas cues. tiones por resolver en su tatea de amonizar el cristianismo con el marxismo. 
Sin duda es aquí legitimo preguntarnos si al menos las contradicciones que atecten a puntos sustanciales no deberían que. dar resueltas antes de asumir en simultaneidad la doble opción.

Efectivamente, algunos parecen haber resuelto previamente su problema personal, adoptando de entrada un marxismo re. ducido a límites componibles con su fe (5). Otros parecen buscar la vía de concordia, por el procedimiento opuesto de estar dispuestos a desideologizar la fe hasta el grado que exija sin más el tipo de marxismo que han adoptado, por razones ajenas a la fe y previamente a la confrontación con ella. Sin embargo, la actitud que tal vez predomine sea la de dejar abierto el problema, confiando que el tiempo lo resolverá (6); se tiene la "intuicion" de que ambos sistemas son en el fondo compatibles y que ambos se reajustarán en la medida necesaria. Ello no impide el que se asuma ya, con toda radicalidad, la militancia marxista en uno u otra de sus formas, sin excluir en principio a ninguna; más aún, oponiéndose a su exclusión. Los problemas que de esas opciones concretas resulten se dejan a la concien. cia de cado uno.

4. Por el tipo de marxismo adoptado. La resolución de alguna de las cuestiones que han quedado abiertas en el apartado anterior la facilita y también la dificulta el hecho de la plurali. dad de sentidos en que uno puede ser y llamarse marxista. También aqui nos ofrece CpS una gran y ambigua diversidad.

a) Diversidad ante todo ya en el nivel de la mera adhesión a la praxis revolucionaria de las tendencias y partidos de inspiración maryista, en orden a la construcción de una sociedad so. cialista. Toda su gama queda recogida en CpS. Las cuestiones aquí implicadas, en relación a la aceptabilidad de ciertas tácticas y procedimientos y a la concreción del tipo de sociedad que se propugna, quedan bastante en la penumbra en el movimiento en cuanto tal.

(5) Esa parece la actitud que refleja la colaboración de J. M." DIEZAlEGPIA: Fe cristiana y praxis marxista, en FEERROMATE, o. c. (nota 3), D. $71-82$.

(6) Nos parece ofectivamente que ésa es la actitud que predomina, al menos entre los pensadores del movimiento en España. Respecto a talia, el núm. 60 de lglesta Viva, ya varias veces citado (nota 1), nos proporciona la material tomado de diversos numeros de la revista Testa en su editorial, y con ella su fundador, BALDUCCl, pero sobre todo un marxista, P. OPLANDO, se cuestionan sobre si la pretendida concordancia entre fe y marxismo en CpS no será sólo un "equivocon y un imposible a eclecticismo ideológicon. De ser así, tendríamos una cuarta forma de amonización, además de las tres que describimos en el texto: la de ta ilusión de la concordia. Esa forma de falsa armonización nos parece la más peligrosa, además de objetivamente poco leal con cristianos y marxistas, ya que camulla la verdadera situación y se presta a la manipulación de las conciencias. Junto con una contestación de G. GIRARDi, véase el materiat de esta polémica en Italia en iglesia Viva, n. 60 (1975), 513-523, 525-533 y $571-579$. 
b) No es claro hasta qué punto la opción marxista de los CpS implica también necosariamente la opción por la ldeologia marxista. Parece dificil separar totalmente en el marxismo la praxis de la ideología. Pero lo que sí es cierto es que de nuevo tropezamos acuí con la diversidad de niveles y sentidos en que ella puede entenderse. Todos ellos son en principlo aceptables para CpS. con la única excepción, tal vez. de acuellas concep. ciones que cierren todo camino a la admisión de un Dios tras. cendente. Aun así, no queda claro cómo esa última limitación es componible con la no exclusion de otros aspectos del mar. xismo que parecen están intimamente vinculados con la nega. ción de un orden trascendente.

Concluyamos este apartado con la siguiente observación: por un lado, ef pluralismo marxista facilita en el seno de CpS la concordia marxista-cristiana. al aceptar como posible correlato de la confrontación un marxismo no radicalizado. Por otro, la dificulta, al negarse en principio el movimiento a excluir ningún tipo de marxismo. Sin embargo, tal vez los cps nos puedan contestar que se trata simplemente de una negaliva inicial, que to unico que pretende excluir son condenas apresuradas, que, además, tienen el peligro de hacerse, no desde la fe, sino desde las ideologias que tienen secuestrada a la fe.

\section{B) Justificación de la opción por el socialismo marxista.}

Los interrogantes que vamos a proponer en este apartado no hacen directamente referencia a la fe. Se limitan a cuestionar sobre la solidez de las motivaciones y razones que conducen a la opción por el socialismo marxista, con su contenido concreto $y$ en las actuales circunstancias.

Para mayor claridad tratamos separadamente de las moti. vaciones que impulsan a la opción, de las razones para aceptar sus contenidos $y$. finalmente, de la racionalidad y prudencia politica de embarcarse ahora y asi en esa aventura.

1. Motivaciones de la opción. Al describir en el apartado anterior la tipología de CpS por la forma de llegar a la opción. hemos ya insinuado la doble motivación que-paralelamente al doble itinerario--conduce de hecho a ciertos cristianos al mar-
xismo.

a) En primer lugar es la simple experiencla de la injusticia y la explotación la que impulsa a algunos cristianos victimas de ella a la participación en la lucha revoluctonaria, desde la que con facilidad muchos desembocan en el marxismo. 
¿Qué decir ante ese hecho? Simplemente que la constación y la explicación psicológica de una conducta nada nos dice todavía de su acierto. Tener motivos no es tener razones. Tene. razones para intentar salir de una situación inadmisible todavía no prejuzga nada de la validez de tal o cual alternativa concreta de solución.

Se nos responderá que precisamente uno de los principales descubrimientos del marxismo consiste en la constatación cientifica de que sólo desde la perspectiva de la clase oprimida es posible interpretar correctamente la historia. No pretendo negar la gran dosis de acierto que encierra esa intuición de Marx; ella ha proporcionado una de sus pistas más valiosas a la "sociologia del conocimienton. Pero conceder que ahi existe una pista y un núcleo de verdad, no es aceptar tal cual toda la teoría marxista de las ideologias (7).

b) La otra motivación real para acceder al marxismo veiamos que consistia en esa dinámica que tiene la fe de buscar una concreción en la que pueda hacerse operativa. Ciertamente la fe cristiana bien entendida seria incoherente sin una proyección práctica hacia la liberación de los hombres y hacla la superación de las estructuras injustas; más aún, ella nos inclina a tomar partido por los oprimidos. Pero intentar la identificación pura y simple de esos contenidos y orientaciones de la fe con la opción de clase (en el sentido técnico que esta expresión adquiere en el marxismo) nos pareceria una extrapolación in. justificada. No estoy insinuando que los CpS cometan esa extrapolación; más bien. cuando se plantean temáticamente el problema, se pronuncian muy claramente por la sustantividad autónoma de la opción por el socialismo. Lo único que quiero deja: sentado es que, tras el análisis de las motivaciones. sigue total mente en pie el problema de la justificación de los contenidos de la opción.

En este contexto conviene, sin embargo, suscitar la siguiente observación marginal: no se ve nada claro cómo desde una perspectiva marxista, que incorpora su teoría del conocimiento y su critica de las ideologías, se puede admitir el que una supuesta ideología (la fe] pueda ayudar a interpretar correctamente la historia y a asumir liberadoramente-incluso contra los propios intereses del que así actúa la causa de los oprimidos. Los Cps son conscientes de esta anomalía y la ponen de relieve para reivindicar la trascendencia y el carácter liberador de la fe. De lo que no estoy muy seguro es de si todos advierten que, de esa forma, han introducido un serio elemento corrector en la teoría marxista de las ideologias.

(7) Acerca de la sociologia del conocimiento del marxismo y de la aphcación que de ella se hace en cps para la lucha ideológica dentro de Iglesia, véase R. ALBERDI: Opción de clase y acceso a la verdad, Iglesia Viva, ก. $60(1975), 535-557$. 
Hagámosle justicia: primeramente lo introducen con su vida y con su obra; sólo secundariamente, con stl reftexión. Ello nos lleva honradamente a preguntarnos fa los que intentamos contribuir con sinceridad, a veces descarnada, al esclarecimien. to del problema desde el plano de la reflexión si no será su obra la más importante, aunque las dos sean necesarias y com.
plementarias.

2. Racionalidad de optar por los contenidos del socialismo marxista. Aun con el riesgo de simplificar excesivamente, nos vamos a restringt en este apartado a enumerar las principales cuestiones, sin desarrollar ninguna. Son estas tres:

a) ¿Por qué ese no tan absoluto a "una tercera via", entre el capitalismo real y el marxismo real? ¿No habria al menos que admitirla como término de un proceso de cambio, iniciado tal vez desde el socialismo?

b) ¿Por qué esa prevención a los socialismos no marxistas y a la democracia formal y sus libertades? ¿Por qué identificar libertades formales con libertades puramente formales? ¿Es posible la libertad sin libertades formales?

c) ¿Qué modelo concreto de socialismo se propugna? Esta última cuestión no se plantea en el seno del movimiento de CpS. pero es insoslayable para cada uno de los CpS.

No sería científico ni racional optar por un socialismo en abs. tracto, eludiendo continuamente la tarea de plasmarlo en un modelo concreto que habria que someter a discusión racional. Parece que, en general, a los CpS no agrada la realidad del socialismo soviético. Pero eso zno es optar por una tercera solucion? Ello, además, ¿no les obliga a plantear y discutir las siguientes preguntas?:

- ¿Cómo socializar la propiedad sin caer en un capitalismo de estado, con una nueva clase explotadora que dispone en propio provecho de los medios de producción y genera así una
nueva clase explotada?

- ¿Cómo socializar el poder, si por una parte se rechaza la democracia formal con sus libertades y por otra no se quiere caer en el totalitarismo ejercido desde un grupo dommante, 0 desde un partido único y ni siquiera en la dictadura del pro-
letariado?

-wComo se socializa la cultura, si por una parte se rechaza el plutalismo ideológico y por otra se pretende evitar el dirigismo ideológico? 
3. Racionalidad politica de la misma opción. Colaborar en el montaje de un aparato de poder (o de conquista del poder) en cuyas entrañas y en cuya dinámica se encierran, confusa e indiscriminadamente, todos los variadísimos objetivos que hemos descrito en el párrafo anterior, es algo que representa sin duda una grave decisión, que no debería tomarse sin una gran carga de prudencia politica y sin ir acompañada de las medidas y cautelas politicas que garanticen contra posibles desviaciones.

No basta tener la intención de contribuir a la construcción de un socialismo de rostro humano; hay también que preguntarse si no se estará contribuyendo al advenimiento de un sistema inhumano, que, una vez establecido, impida despóticamen. te toda posible evolución.

\section{C) Compatibilidad del marxismo con el cristianismo}

Desde el punto de vista de sus aspectos formales, esta cuestión, central para nuestro propósito, ha sido ya tratada en la primera parte de este trabajo y volveremos a ella en la tercera. Nos parece. sin embargo, necesario recordar aquí lo siguiente: los CpS describen, a veces, su aceptación simultánea del cristianismo y del marxismo con la expresión "unidad dialéctica". Esa terminología, utilizada por un marxista, nos gusta muy poco. pues en la concepción marxista de la dialéctica (desarrollada en sus tres leyes clásicas) uno de los contrarios en conflicto termina siempre por eliminar al otro, produciéndose entonces el salto cualitalivo. Es claro que si la dialéctica se entiende así el marxismo piensa que el contrario eliminado sería la fe.

Ciertamente los CpS no utilizan la expresión en ese sentido técnico. El comunicado final del encuentro de Bolonia (septiembre, 1973), clásico a ese respecto, habla de "las exigencias de nuestra fe y las del compromiso revolucionario, unidas en una relación dialéctica de recíproca critica y fecundación" (8). Se admite, por tanto, al menos teóricamente. que el influjo debe ser reciproco. coincidiendo así con lo defendido por nosotros en la primera parte. Pero, como también ya hemos advertido, el mecanismo funciona, de hecho, muy suavemente con la dirección contraria, es decir, en la de la interpelación de la fe respecto al marxismo. Ello es tanto más grave cuanto que, como acabamos de ver, existen en la teoría y en la praxis marxista justificaciones de ese modo de proceder. De confirmarse esa sos. pecha, el pretendido ámbito de diálogo se habría degradado y convertido en simple instrumento de manipulación.

(8) Véase en FIERBO-MATE, o. c. (nota 3), p. 336-337. 
Ello nos obliga a ser totalmente francos y sinceros en este apartado. Nadie puede esperar que iniclemos ya, aqui, la confrontación cristianomarxista. Pero podemos contribuir a su recto planteamiento estableciendo un catálogo inicial de cuestiones pendientes, en las que la fe parece interpelar seriamente al mar. xismo. Dejamos abierta la tarea de dilucidar cuáles de estas interpelaciones poseen o no peso real, bien porque el marxismo no afirme lo que parece afirmar, bien porque la interpelación que aparentemente se hacía desde la fe, en realidad se haya hecho desde una comprensión ideologizada de la fe. También cabe la posibilidad de que el marxismo, estimulado por nuestra interpelación, refome, o deba reformar a partir de sus proplos principios, ciertas afirmaciones insostenibles.

Queda, pues, claramente establecido lo unico que aqui pretendemos: ayudar a precisar las áreas de confrontación, con especial insistencia sobre aquellas que tienden a dejar en la penumbra los círculos de CpS. De camino, insinuamos a veces en qué puntos nos parece que seria posible un repliegue, por parte marxista o cristiana, sin renegar de su propia esencia. Si explicitamos más los repliegues marxistas, es porque los CpS exigen ya suficientemente en su "lucha ideológican muchos repliegues cristianos. Sistematizamos to esencial de este catálogo en estos
dos grandes capitulos.

1. El monismo de la ideología marxista. Nos sirve esta expresión para sintetizar en ella toda una serie de reservas que suscita la ideología marxista en sus varios niveles de com.
prensión.

a) Niveles de comprensión de la ideología marxista. En nues. tra opinión uno puede ser y llamarse legitimamente marxista fin. cluso desde el punto de vista ideológicol si acepta el pensamiento de Marx en alguna de estas cuatro formas, que pueden o no simultanearse.

1. Como un método y una ciencia, que tiene por objeto la interpretación de la historia, de tal forma que permita contribuir a su correcta transfomación. Esa ciencia tiene sus leyes extraidas de la experiencia, cuyo valor y alcance ha de ser continutamente contrastado, revisado y comprobado.

2. Como una sociología del conocimiento, muy relacionada con la ciencia anterior y con sus mismas caracteristicas cientificas. Su principal mérito ha consistido en poner de relieve el influjo de los intereses económicos y de la perspectiva de clase en la configuración de las ideologías.

3. Como una filosofía de la historia, entendida en términos de "materialismo histórico", es decir, como una iluminación omnicomprensiva de ella, en la que todo se explica wen último tér. 
mino" por la dinámica dialéctica de las formas y de las rela. ciones de produccion. El materiallsmo histótico e3, además, tuna aplicación del "materialismo dialéctico", que por ahora basta entenderlo como "realismo dialéctico", en el sentido de que en la historia no es la idea la que determina la realidad, sino la realidad material (es decir, los factores económicos) la que determina todo lo demás $y$, especificamente, las formas de pensar.

4. Como una filosofía omnicomprensiva, en términos de "materialismo dialéctico", pero ahora entendido, no sólo como "realismo dialécticon (opuesto simplemente a "idealismo dialécticon en el plano de la teoría del conocimiento), ni sólo como "materialismo históricon (en el sentido ya definido de explicación dialéctica de la historia a partir de la economia), sino con la pretensión de ampliar su objeto, desbordando el ámbito de la historia humana, para fundar tambien una "Filosofia de la Naturalezan y una Ontología o Metafísica de corte materialista, que excluye positivamente a toda realidad espiritual y a toda transcendencia.

b) Critica al monismo marxista y sugerencias reductoras. Lo que presta al marxismo dogmático gran parte de su atractivo y fascinación constituye a su vez su vicio más radical: su simplismo unificador, que lo convierte en un sistema de un único factor último. Esa tendencia monista se muestra ya en el intento. siempre renovado, de mantener vinculados esos cuatro niveles en un bloque monolítico. El marxismo más extremo y rígido considerará una inadmisible herejía el simple intento de plantear una distinción. Otros tal vez la admitan, pero casi nunca se expresan con la suficiente claridad para que no sea de temer una recaida en el dogmatismo totalizante.

Como tal bloque-al que parecen apegados los marxistas reales que han llegado al poder.-ese marxismo es inadmisible para un cristiano. Este no puede aceptar, ni un "materialismo dialéctico" que excluya toda transcendencia (de Dios y del hombre, en cuanto persona con inteligencia y libertad) ni siquiera un "materialismo histórico" que reduzca (aunque sea "en último térnino") toda la marcha de la historia y todo el mundo del espíritu les decir, todo el ejercicio de la inteligencia y de la libertad humana, incluida la fe y la misma obra de Cristo a simple reflejo ideológico y a función más o menos lejana de la economía. Mientras esa concepción absolutamente unidimensional no se descalifique de raíz, ella generará y hará retoñar siem. pre de nuevo - a despecho de débiles reacciones que a veces se provocan, cuando la exageración llega, p. ej, a los brutales Iimites de un stalinismo-las actitudes intolerantes y dictatoriales, que de entrada excluyen todo diálogo no oportunista. En efecto: nada válido se espera de aquellos que por definición están deformados e ideologizados y no forman parte de las van. guardias lucidas que comprenden la marcha de la historia. 
Tal vez por esa razón también la uciencin" marxista fosta amomazada del virus del monismo, en tanto no introduzca explicitamente algunas correcciones en su misma metodología. Debería, pues, abandonar la pretensión-nunca demostrada-de explcarlo todo (aunque sea "en ultimo términon) por el sólo factor económico, para considerar a ese factor como factor prevalente o incluso como simple factor importante. Yo no tendria incon. velente en admitir ahora mismo, como hipótesis científica de trabajo (y mayores pretensiones no puede exlgir un método cientifico), el que las acciones y los pensamientos humanos se explican en el 99 por 100 de su entidad por condicionamientos, en último término, económicos. Basta ef 1 por 100 restante para hacer ya sitio a la fe y a las otras dimensiones humanas (racionalidad, generosidad, etc.), con lo que la diferencia cualitativa de una situación a otra es absoluta. Además. en cuanto ello se acepte surgirá una nueva discusión cientifica, encaminada a precisar si los factores extraeconómicos no cualificarán fincluso en último término) a la historia humana en una proporclón
mayor.

Mientras esa corrección no se introduzca, la pretondida "ciencian marxista continuará stendo un dogmatismo más o menos camuflado. No basta para superato aludir a la "relativa autonomía de las otras dimensiones, pues nunca se concede que esa autonomia sea originaria y alcance a la raiz.

He expresado con toda sinceridad mi pensamiento y lo be hecho con la intención de ofrecer una salida al bloqueo en que vive estancada la ciencia marxista. Así como los marxistas y los $\mathrm{CpS}$ piden una desideologización de la fe. asi habria también que pedir una desideologización paralela del marxismo cientifi. co. Sus fecundas potencialidades están "secuestradas" por una ideología desmesurada, instrumentalizada una veces al servicio de intereses de grupos establecidos en el poder y utilizada otras por el natural deseo de eficacia inmediatista en la superación radical de las injusticias. Pero ese secuestro opera también contra la eficacia, pues crea un clima de recelo que impide a muchos la aceptación y utilización de los instrumentos concep. tuales válidos que hay en la ciencia marxista.

2. La praxis politica. La desmesura totalizante de la ideología marxista se espeja también en su concepción de la praxis politica. Desgraciadamente de esta forma se obstaculiza de nue. vo el que sus innegables valores de eficacia puedan ser asumidos sin recelos por muchas personas-cristianas o no-que no logran hacerlos compatibles fen la forma en que son propug. nados) con una conciencia moral que respete la dignidad del
hombre.

La raiz del problema no está tanto en el hecho y en la justificación en la lucha de clases, sino en las calidades que ésta 
adquiere en el marxismo clásico y tiende a adquirir en todo marxismo. Todo lo demás es simple consecuencia. De ahi derivan las deformaciones de la praxis politica marxista, en la fase de lucha por el poder y en la fase de ejercicio del poder, en orden a la represión de la clase explotadora y a la construcción del socialismo. De la tercera fase no nos vamos a ocupar: la profecía de que el estado se marchitará y ningún poder será ya necesario (porque, una vez eliminada la propiedad privada y la división de la sociedad en clases, ya no habrá ninguna posibilidad de opresión nos parece una ilusión utópica fruto de su sim. plista concepción monista.

a) La lucha de clases. Tal vez extrañe a más de uno el enfoque que voy a dar al tratamiento de este punto tan controvertido. Creo que la oposición cristiana a la concepción marxista de la lucha de clases no tanto hay que ponerla en el hecho mismo de la lucha y en su justificación, cuanto en las caracteris. ticas cualitativas que esa lucha adquiere, si acepta con radicalidad la concepción marxista que ya hemos criticado. Analice. mos los dos aspectos del tema:

1. Es falso que los marxistas quieran la lucha de clases. Todo lo contrario: tienden a la superación de una organización social, que se basa constitutivamente en un enfrentamiento estructural. Lo que desean es la desaparición radical de esa lucha y el establecimiento de una sociedad sin posibilldad de enfrentamientos estructurales.

En la medida en que ese enfrentamiento estructural existe (y ciertamente existe en el capitalismo) y en la medida en que sea posible construir un tipo de socledad sin o con menores enfrentamientos estructurales (y ello también parece posible, so pena de que queramos, sin más, canonizar al capitalismo), en esa medida-sea la que sea-un cristiano no puede menos de aplaudir ese intento. No entramos en el tema del análisis concreto de las causas profundas de los enfrentamientos estructurales, pero creo que podemos conceder al marxismo, que en ello juega un gran papel. la forma de estar estructurado el régimen de propiedad.

Sigamos adelante: aun con los correctivos que haya que introducir en una concepción marxista rígida (de un solo factor) en orden a determinar qué tipo de sociedad habria que promover, lo que sí es claro es que esos proyectos de cambio estructural chocarán con los intereses de clases en los sectores que ahora están injustamente privilegiados. Al llegar a este punto, de nuevo hemos de reconocer la gran carga de verdad que late en estas dos constataciones del marxismo y que nosotros vamos a formular con una cierta moderación. Primero: las personas y grupos que ocupan en la sociedad una posición de injusto prìvilegio estructural, normalmente se opondrán a cualquier modi- 
ficación de esa situación. Segundox dichos grupos elaborarán todo un montaje ideologico, en el que, tras aparentes razones, se enmascara y justifica, ante los ojos de los demás y ante los suyos propios, la injusticia de las estructuras vigentes. Parale. lamente los sectores oprimidos, aunque tampoco estén libres del peligro de deformar los problemas, querrán el cambio y tendrán los ojos más lúcidos para advertir su necesidad.

Puestas asi las cosas, la lucha (ideológica y real) parece en alguna medida necesaria, sin que todavía ello prejuzgue nada de los medios. Y lucha ciertamente revolucionaria, no necesa. riamente en el sentido de ser violenta (que oso es un medio). sino en el sentido de tender a camblos estructurales profundos. Se podrá exigir como condición previa un sincero análisis y un intento de dílogo sobre la justicia de lo que se pide, pero sería utópico pensar que las reformas profundas se pueden hacer sin serios enfrentamientos. Al llegar a este punto es donde la lucha puede llegar a imponerse. Afirmar lo contrario seria aceptar indefinidamente la otra lucha, estabilizada en la opresión estructural. El argumento de fondo del marxismo tal vez se pueda reformular asi: la lucha de clases se justifica como agudización coyuntural y pasajera (por parte del débil) de una estructura continuada de lucha y de opresión (montada por el fuerte) en orden a la eliminación de esa estructura y consiguientemente a la desaparición de la misma lucha. Difícilmente nos atreve-
rímos a negar toda justificación a una lucha asi planteada.

2. Se nos podrá replicar que la lucha descrita en los párrafos anteriores no es ya la lucha marxista. Eso no es del todo verdad. En ellos no se han modificado sustancialmente los argumentos del análisis marxista en favor de la necesidad de esa lucha y de su justificación, aunque ciertamente se han introducido algunas correcciones en su enfoque, que adelantan el tema de este párrafo: el de las cualidades que la lucha de clases adquiere necesariamente en el marxismo rígido de un solo factor. Es aqui donde centramos nuestra interpelación critica.

La simplificación inherente a la concepción monista del marxismo muestra al máximo su capacidad deletérea y deshumanizante, cuando se aplica con todo rigor lógico al hombre. Porque el hombre deja entonces de ser persona, para convertirse en una función y un subproducto de las relaciones de producción. Su personalidad se volatiliza para quedar ("en ultimo término") de. finida por la forma de estar situado en el proceso productivo. Si queda situado en el bando opuesto, nada valioso puede reconocérsele: sus pensamientos serán construcciones ideológicas: las decisiones de su voluntad sólo pueden estar al servicio de intereses opresores; su entera proyección vital irá a contracorriente del sentido de la historia. De él no puede brotar nada originariamente válido: ni una contribución a la verdad, ni un gesto de verdadera generosidad que vaya contra sus intereses, 
ni siquiera una conversión. En camblo, los que están en el bando de los oprimidos y no lo están del todo según la curlosa lnterpretación de Lenin, sino aquellos que tengan su mente homo. logada con la del partido $y$, en la práctica, con la de sus dirigentes), ésos son por definición los lúcidos, los justos y los eficaces, pero sólo porque sus "intereses" coinciden con las exigencias objetivas de la marcha de la historia. Como se ve. tampoco la personalidad de éstos queda en absoluto salvaguardada. Unos y otros son el fondo (en ültimo término), simple función de la sifuación: el hombre ya no puede ser concebido como un ser que, en último término (aunque dentro de ciertos limites y condicionamientos), está dotado de una capacidad intelectiva capaz de iluminarlo, que a su vez le permite elegir consciente y responsablemente entre el bien y el mal y lo convierte, por tanto, en fuente originaria de generosidad y amor, de injus. ticia y egoismo.

Miradas así las cosas el adversario se convierte necesariamente en enemigo total, o mejor aún en objeto o mecanismo amenazador absolutamente despersonalizado que hay que eliminar o reprogramar (lavado de cerebro). Si una concepción de ese tipo no se supera (y su superación supone el rechazo explicito de algunas tesis del marxismo), de nada sirve el que algunos CpS me den una respuesta ideológica y digan que se puede combatir al adversario con amor. No basta yuxtaponer el substantivo amor al verbo combatir; este último tiene en el marxismo un sentido muy concreto y radical; en cambio, la palabra amor, en ese contexto, puede no llegar a significar nada. Hay que dejar claro en qué medida la presencia del amor modifica el contenido significativo de la palabra combatir, y ello no sólo en el terreno inoperante de los sentimientos, sino modificando la forma de combate. En el fondo lo que está en juego es la concepción del sujeto combatido: no es igual combatir a personas que a objetos y máquinas o, lo que sería lo mismo, a hombres concebidos como tales.

El cristianismo no elimina la posibilidad y la legitimidad de enfrentamientos enérgicos entre los hombres; lo que nunca podrá admitir es que en la lucha se volatilice el carácter personal del adversario y el de uno mismo. Ello en concreto quiere decir que a nadie se le puede negar radicalmente la capacidad de acercarse a la verdad, de tener un gesto de generosidad, de obrar el bien y el mal con responsabilidad, de "convertirse" como persona. Es más humano enfrentarse a un malvado como malvado--to cual supone que entra también en juego el análisis de la culpabilidad subjetiva-que el frío enfrentamiento marxista ante el adversario de clase, al que hay que eliminar o curar lob- 
jetivamente: como a un perro rabioso), pero nuca escuchar o
intentar porstatir (a)

Correlativamente, para que el enfrentamiento sea humano, se requiere reconocer en si mismo y en los compañeros de clase la posibilidad de error, de pasion, de maldad; y ello no sólo a par. tir de la pecabilidad esencial del ser humano, sino también por el reconociniento humilde de que todos estamos objetivamente
inmersos en estructuras deformantes.

Parece claro que una lucha emprendida desde estos presupuestos sería una ducha cualitativamente diferente.

b) La conquista del poder y el uso del poder conquistado. La concepción marxista de la lucha de clases, sin las correcclones cualitativas que acabamos do apuntar, es la que explica fundamentalmente las objeciones que desde la óptica de una ética cristiana se pueden hacer a la praxis politica del marxismo, tanto en la fase de conquista del poder fen lucha con la clase dominante) como en la fase de latlización del poder para la construccion del socialismo fen lucha tambien con esa clase. que ahora ha pasado a ser y definirse como oprimidal.

1. En la fase de conquista del poder, el marxismo rígido, por su concepeion del hombre y del adversario como mero obstáculo objetivo, está siempre en peligro de establecer como supremo valor la eficacia a toda costa. Ello implica, al menos en la práctica, la consagración del principio de que el fin justifica los medios, con tal de que ello impulse hacia adelante la causa del proletariado. En pura lógica no habría entonces nada que oponer a la utilización de diversas tácticas, según convenga y con la única condición de que no se hagan disfuncionales. Se puede pasar asi de la actitud suave a la violencia; del diálogo oportunista y manipulador al bloqueo de dicho diálogo, cuando con él se pierden posiciones; de la democracia como medio instrumentalizado a la imposición autoritatia. Mientras la misma la ética politionbre no sea considerada como fundamento ético. al "quén y al resultado de la acción. "cómo". sino únicamente

(9) Ponemos la fuerza de nuestra reflexión no en la superación del odio sino en la superación de la objetivación y cosificación deshumanizante. En ese sentide empleamos la comparación del perro rabioso. El odio supone, al menos, ef reconocimiento del otro en cuanto persona. El marxismo conseobjetos o animales daninos ve en los adversarios personas malvadas, sino burguesia como "certosnos. Pasolini, en la pelicula Porcile, objetiva a la ralmente a unas personss at parecer, to hace no como el que cellfica mopor lo que son: como producto se han hecho malvadas, sino deflniendolas Esos cerdos teminan devorando despersonalizados de los intereses de clases. in desobedienten. 
2. La misma concepción del hombre y de la lucha de clases que hemos criticado es la que se aplica-si no es sometida a las apuntades correcciones-en la fase de utilización del poder, con el agravante de que entonces se tiene al adversario totalmente en las manos. Pero una concepción cristiana del hombre no permite que el adversario vencido sea considerado como un ser absolutamente sin derechos. Los más intocables y sagrados - los especificamente humanos-son precisamente los que quedan garantizados por las denostadas libertades formales, libertad de pensar y creer, de opinar, de manifestar la opinión y disentir, de reunión y asociación libre, de participación politica (10). Todo ello debe ser integrado en un proyecto marxista de sociedad que aspire a llamarse humana y sea por ello aceptable para un cristiano.

3. Orras cuestiones. Sin imposibles pretensiones de exhaustividad, pero con el deseo de recoger unitariamente una serie de aspectos de la confrontación cristiano-marxista, que no siempre se ponen suficientemente de relieve, enumeramos todavia los siguientes temas:

a) Relación entre los dos principios motores del cristia. nistno y del marxismo: el amor y el interés de clase.

b) Opción de clase y opción cristiana por los pobres y los oprimidos.

c) Signos de los tiempos y desideologización de la fe.

d) Luchas de clases y lucha cristiana por la justicia.

e) Conversión personal y cambio de estructuras.

\section{III.--POSIBLES RESULTADOS DEL. DIALOGO CRISTIANO. MARXISTA}

Una vez localizados los problemas más conflictivos del encuentro cristiano-marxista, volvamos a empalmar con nuestras consideraciones de la primera parte, para preguntarnos a qué resultados podría, en principio, conducir un diálogo planteado sobre aquellas bases. Las salidas pensables son las dos siguientes:

A) Acercamiento recíproco y profundización de cada dialogante en su linea especifica.

(10) El tema de la relación entre libertades formales y derechos sociales lo hemos tratado en MATIAS GARCIA: Concepción tensionat de los derechos del hombre: Mundo Social, $n, 154$ (1968), 28 -32. 
Tal como nosotros planteábamos el diálogo, éste, si tiene no. billdades do extro, no debe conducir a la eliminación de una de las partes. Vimos alli que, si se logra un acercamiento en la forma por nosotros defendida, el cristianismo saldrá del proceso siendo más cristiano y el marxismo siendo más marxista; en ambos casos se habrá avanzado, tanto en la línea de la coherencia de in fe, como en la de la raclonalidad cientifica.

Advirtamos, sin embargo, que ser més cristiano es ser más fiel a la persona, al mensaje y a la intención de Jesús; en cambio, ser marxista no tiene por qué consistir en una fidelidad $\mathrm{i}$ teral a la persona o al pensamiento de Marx y de Engels, sino más bien a su intulción de fondo, en orden a hallar un método de análisis riguroso y científico de la historia y sus contradic. ciones, que nos sirva para interpretarla y sobre todo para impulsarla correctamente. Este método y los análisis que de ahí resulten valdrán no por proceder de Marx. sino por la fuerza de su racionalidad interna y su verificabilidad práctica. Pero el análisis cientifico de la realidad puede obligar a efectuar reajustes en algunas de las conclusiones a que Marx llegó: puede obligar incluso a introducir matizaciones en el mismo método de análisis; finalmente, puede descubrir que parcialmente ese método científico se extrapoló tal vez (como tal ciencia) y se erigió indebidamente en filosofía e incluso en religión. En todos esos casos, los reajustess que habrá que introduclr en el marxismo lo harán tal vez menos (o más) leninista, menos (o más) stalinista, trotzkista, maoista, titoista o, en otro orden, menos (o más)
neo-marxista (11).

Más aun, puede llegar incluso a ser menos "marxiano", pero. en la medida en que ello responda a una dinámica de racionalidad y de coherencia con la realidad, será más profundamente marxista. Otra cosa sería degradar el marxismo al nivel de un autoritarismo mitico.

\section{B) Desaparición de una de las partes.}

No se nos oculta que un diálogo asi entendido en principio podria conducir también a la disolución de una de las dos partes en conflicto.

Los reajustes en el marxismo-más o menos estimulados por el cristianismo y por otras corrientes de pensamiento, pero en último témino realizados en su seno e impulsados por su propia dinámica de racionalidad cientifica-podrian conducir un dia a la comprobación de que ni siquier "as intuiciones centrales

(11) En cualquiera de sus posibles lineas e interpretaciones: Horkheimer, Adorno, Habermas, Marcuse. Althusser, Sarte; 0 incluso Mambeim, 
de Marx fueron válidas, o al menos que ya no lo son para el análisis de una sociedad profundamente modificada. Se trataria, como en otros muchos casos de la historia, de una teoria cien. tífica que se terminó por comprobar que era incorrecta o que quedó superada.

A su vez, y desde su actual punto de vista, un marxista "ortodoxo" podrá sostenor que tal vez llegue un día en que la religión se desmorone y desaparezca, confirmando así una tesis del marxismo clásico, según la cual toda religión os un subproducto ideológico de unas determinadas relaciones de producción y una alienación derivada de la bésica alienación económica provocada por la sociedad clasista. En estricta ortodoxia marxista, la fe no desaparecerá por la persecución del marxismo, sino que ella misma se marchitará, una vez que se elimine la raíz de su ser ilusorio.

\section{C) Conclusión: aceptación del reto y juego limpio.}

Con tal de jugar limpio, admitamos todos el reto del enfrentamiento. Es legitimo que cada uno apueste de entrada por el resultado. El marxismo ortodoxo lo hará tal vez por la desaparición de la religión; el cristiano que opine que no hay nada aprovechable en el marxismo y que éste no tiene ninguna interpelación válida para el creyente puede legítimamente pensar el que un día aparecerá con claridad la absoluta irrelevancia del marxismo. Otros pensamos que de la confrontación puede salir un cristianismo purificado y desideologizado, pero también un marxismo adogmático y bastante transformado, que renunclará a algunas de sus tesis clásicas, entre ellas la proclamación positiva del ateismo (12).

(12) Creo que 3. I. Gunzález Fats, on un contexto muy diferente, nos dice algo muy parecido: "Si, ahora desde este esquema, volvemos los ofos a lo que llamamos "derecha" e "izquerda" cristológicas, nos encontraremos con la siçuiente paradoja, que parece inesperada, pero que viene a coincidir con la tragedia historica de ambas posturas: la derecha temina afimando falsos dioses, porque Dios sóło es afirmable en el hombre. Mientras que el peligro de ta izquierda es acabar destrozando al hombre, porque el hombre sólo es afirmable desde Dios" (Humanidad nueva. Ensayo de cristologia, Ed. EAPSA, Madrid, 1974, 507-508). La observaclón vale para el dialogo cristiano-marxista, para ese mismo diálogo en el seno de los CpS y para el dítogo intraeclesial. En todos los casos, el intento de afirmar en exclusividad a Dios o al hombre se resuetve paradójicamente en la negación de Dios a del hombre. El estimulo de humanismo eficaz del marxismo puede ayudar a desideologizar en sentido cristiano al cristianismo, y la afirmación de Dios del cristianismo puede y debe salvar al marxismo de sus elementos deshimanizantes. El mismo González Faus, en las páginas que siguen (508-512), nos hace ver como la interpretación de la fe está siempre amenazada de parcialismos y desviaciones, y que las mismas definlclones dogmáticas que prestaron un servicio de interpretación correcta de ella en un determinado contexto cultural pueden dat pio a nuevas desviaciones desde contextos diferentes. 
Sospecho que muchos CpS y algunos marxistas piensan ya de forma muy parecida, annquem on relación a los cambios y reajustes necesarios en el marxismo-..se expresen en términos mucho menos drásticos, por temor tal vez de tomper la frágil concordia. Los CpS explicitan con toda claridad la necesidad de desideologizar a la lglesia y purificar su propia autocomprensión, pero-al menos de puertas afuera-son enormemente cautos en la crítica (autocrítica) del marxismo que han adoptado. Tal vez ello se deba a una táctica inicial, incluso inconsciente, en orden a probar (y a probarse a si mismos) con los hechos la sinceridad de su opción y en orden a romper los recelos que existen por parte marxista. Pero si se ha de llegar a un acercamiento, que se inlcie con bases mis sólidas y racionales y con mayores perspectivas de avance, si se quieren crear las bases para una unión de todos aquellos que desearian poder estar juntos tomando partido por los oprimidos en la construcción de una sociedad más justa, entonces habria también que procurar el que por parte marxista se haga un esfuerzo por ellminar (y no sólo camuflar) las raices de los muy justificados recelos que la praxis y la teoría marxista suscitan todavía a los cristianos, por muy desideologizados que éstos estén.

Expresemos todo ello de otro modo. Tal vez la intuición fundamental de los cps puede describirse asi: en el mundo real sólo existen dos grandes alternativas a la hora de optar, no por una teoria, sino por una forma práctica de influir sobre el conjunto de la estructura social: la alternativa que encarna la corriente liberal-capitalista y la que encama la corriente socia. lista de inspiración marxista. A los cristianos no les gusta de entrada ninguna de las dos, pero hay que optar. De hecho han optado en el pasado por colaborar con la alternativa liberal-capitalista, si bien con el propósito de modificarla y hacerla componible con los valores cristianos. Tras muchos decenios de continuas frustraciones, en que el capitalismo en su conjunto muestra, cada vez con más claridad, su entraña anticristiana (por antihumana), hoy hay muchos que empiezan a preguntarse sl no valdría la pena intentar el proceso de transformactón tomando ahora como punto de partida la otra alternativa real.

Ese planteamiento no carece tampoco de dificultades; principalmente la que deriva del explicito y militante ateismo del marxismo que encarna esa alternabiva real, y también la del temor a cerrarse el camino de vuelta, si se colabora a la instauración de un poder que por su propia teoria (y desde luego por la práctica, nunca desmentida, que rige en esa alternativa) se organiza totalitariamente y puede hacer ilusoria toda esperanza de transformación. Pero, además, en toda hipótesis, ese plan. teamiento (que tiene ciertos visos de racionalidad) numca consiste en aceptar la alternativa socialista tal cual, para dejata ast, sino, a lo mas, de acoptatia lal cual, pero inicamente como 
punto de arranque real, en el que se asumen con toda sinceridad intuiciones básicas muy importantes, pero al que también se contempla como algo que necesita muy serios reajustes. Respecto a ello hay que tener claridad desde ol principio, no con actitud cerradamente dogmática, pero sí con clara conciencia de dónde están los interrogantes que esa alternativa real suscita. $Y$ ello, no sólo a un cristiano, sino incluso a una persona que, llevada de su propia racionalidad, no ve de entrada que todo en el marxismo sea tan lúcido ni tan humanizante.

Con mis reflexiones sólo he intentado aportar mi contribución al planteamiento de este importante diálogo, y eflo no con una actitud condenatoria, sino con el deseo de contribuir a que la aventura, si hay que emprenderla, se aborde con lucidez.

Posiblemente en ulteriores colaboraciones desarrollaré algunos de los temas que ahora me limito a apuntar e intentaré precisar más lo que hoy por hoy me parece por ambas partes irrenunciable y a lo que me parece se puede renunciar para avanzar en el camino de la concordia. 